\title{
Formate dehydrogenase (FDH1) localizes to both mitochondria and chloroplast to play a role in host and nonhost disease resistance
}

Seonghee Lee ${ }^{1,2 *}$, Ramu S. Vemanna ${ }^{1,3}$, Sunhee $\mathrm{Oh}^{1}$, Clemencia M. Rojas ${ }^{1,4}$, Youngjae $\mathrm{Oh}^{2}$, Amita Kaundal ${ }^{1,6}$, Taegun Kwon ${ }^{1}$, Hee-Kyung Lee ${ }^{1}$, Muthappa Senthil-Kumar ${ }^{1,5}$, and Kirankumar S. Mysore ${ }^{1 *}$

${ }^{1}$ Noble Research Institute, LLC, Admore, OK, United States

${ }^{2}$ Gulf Coast Research and Education Center, Institute of Food and Agricultural Science, University of Florida, Wimauma, FL, United States.

3 Current Address: Laboratory of Plant Functional Genomics, Regional Center for Biotechnology, Faridabad, Haryana, India

4 Current Address: Department of Entomology and Plant Pathology, University of Arkansas, Fayetteville, AR, United States

${ }^{5}$ Current Address: National Institute of Plant Genome Research, New Delhi, India

${ }^{6}$ Current Address: Department of Plants, Soils and Climate, Utah State University, Logan, Utah, United States

*Corresponding authors: seonghee105@ufl.edu and ksmysore@ noble.org 


\section{ABSTRACT}

Nonhost disease resistance is the most common type of plant defense mechanism against potential pathogens. In this study, the metabolic enzyme formate dehydrogenase (FDH1) was identified to be involved in nonhost disease resistance in Nicotiana benthamiana and Arabidopsis thaliana. In Arabidopsis, AtFDH1 was highly upregulated in response to both host and nonhost bacterial pathogens. Arabidopsis Atfdhl mutants were compromised in nonhost resistance, basal resistance, and gene-for-gene resistance. The expression patterns of salicylic acid (SA) and jasmonic acid (JA) marker genes after pathogen infections in Atfdhl mutant indicated that SA is most likely involved in the FDH1-mediated plant defense response to both host and nonhost bacterial pathogens. Previous studies reported that FDH1 localizes to only mitochondria, or both mitochondria and chloroplasts. Our results showed that the AtFDH1 localized to mitochondria and the amount of FDH1 localized to mitochondria increased upon infection with host or nonhost pathogens. Interestingly, the subcellular localization of FDH1 was observed in both mitochondria and chloroplasts after infection with a nonhost pathogen in Arabidopsis. We speculate that FDH1 plays a role in cellular signaling networks between mitochondria and chloroplasts to produce coordinated defense responses such as SA-induced reactive oxygen species (ROS) generation and hypersensitive response (HR)-induced cell death against nonhost bacterial pathogens.

Keywords: biotic stress, plant defense response, hypersensitive response, programmed cell death, reactive oxygen species 


\section{INTRODUCTION}

Nonhost resistance provide basic protection to plants and are also the most durable form of resistance to the majority of potential pathogens [1-5]. In general, both basal and nonhost resistance are controlled by quantitative trait loci (QTL). Disease resistance traits conferred by these QTLs have been widely used for developing new varieties for disease resistance [4, 6-9]. In addition to QTLs, a number of studies have identified major plant genes involved in nonhost resistance against fungal and bacterial pathogens [4, 5, 9-11]. However, the mechanism of nonhost resistance is not well understood. Nonhost resistance against bacterial pathogens can be broadly classified as two types; type I (no visible hypersensitive response [HR] cell death) and type II (HR cell death) nonhost resistances [10]. The efficacy of nonhost disease resistance is based on the recognition of pathogen-associated molecular patterns (PAMPs) and/or pathogen effectors. PAMPs are mainly located at the plasma membrane where the PAMP-triggered immunity (PTI) could be induced as the first defense barrier against various pathogens $[12,13]$. One known PTI response is stomatal closure that is circumvented by the phytotoxin coronatine (COR) produced by the host pathogen P. syringae pv. tomato DC3000 [14]. COR has structural and functional similarity to jasmonates and jasmonic acid-isoleucine (JA-Ile), and contributes to the virulence of $P$. syringae pv. tomato DC3000 $[15,16]$. COR disrupts the accumulation of the plant defense hormone salicylic acid (SA) for stomatal reopening and bacterial propagation in both local and systemic tissues of Arabidopsis [17]. COR is also involved in promoting the entry of nonhost bacterial pathogens via stomata and nonhost bacterial growth at the initial stage of infection [18]. In addition to PTI, a number of pathogen effectors secreted into host cells can also induce 
another type of defense response referred to as effector-triggered immunity (ETI) [19, 20]. ETI is typically associated with resistance proteins belonging to the nucleotide-binding domain (NBD) and leucine-rich repeat-containing (NLR) family. ETI triggers a type of cell death known as the HR [21]. Despite the plant immune systems, compatible host bacterial pathogens in susceptible plants suppress both basal and nonhost resistance responses to cause disease.

Formate dehydrogenase (FDH1) is a nicotinamide adenine dinucleotide (NAD+)dependent enzyme that catalyzes the NAD-linked oxidation of formate to carbon dioxide. As a component of one-carbon metabolism in plants, most FDHs play an important role in response to various stresses in higher plants [22-25]. A previous report has shown that FDH1 regulates programmed cell death (PCD) in pepper against bacterial pathogens [23]. There is contradictory information regarding the localization of FDH1 in plant cell. According to the study by Choi (2014), FDH1 localizes to mitochondria and plays a role in hypersensitive cell death and defense signaling pathway against the bacterial pathogens in pepper. Several other reports also suggest mitochondrial localization of FDH1 in tobacco $[26,27]$. Interestingly, few reports described that FDH1 targets not only mitochondria but also chloroplasts for its biological function [28, 29]. Chloroplast and mitochondria are the major targets of plant pathogen effectors, and targeting of these organelles by effectors inhibits the production of defense molecules including reactive oxygen species (ROS) [30, 31]. Chloroplasts play a major role in generating ROS and nitric oxide to trigger defense responses such as PCD and HR against bacterial pathogens $[32,33]$. Mitochondria and chloroplasts also have been reported as the initial organelle to recognize bacterial effectors and to trigger plant immunity against bacterial pathogens 
$[34,35]$. In other studies, the co-localizations of mitochondria with chloroplasts has been well characterized [36-38]. The physical interactions between mitochondria and chloroplasts would provide the means of transferring genetic information directly to the organelle genome, as well as to mediate signaling transduction [39-42]. However, how chloroplast and mitochondria are functionally integrated for bacterial disease resistance is not well understood. Particularly, previous conflicting results regarding the cellular localizations of FDH1 may suggest possible roles of FDH1 in the chloroplast as well as mitochondria for bacterial disease resistance.

In the current study, we demonstrated a novel role of FDH1 in nonhost disease resistance in Nicotiana benthamiana and Arabidopsis. The cellular localization of FDH1 was confirmed to be mitochondria, but it was also found that the protein targets to chloroplasts for the defense responses against host and nonhost bacterial pathogens. We speculate that FDH1 may coordinate mitochondria- and chloroplast-mediated defense responses to bacterial pathogens in plants.

\section{RESULTS}

\section{Formate dehydrogenase is involved in nonhost disease resistance}

Using virus-induced gene silencing (VIGS)-based forward genetics screening in $N$. benthamiana, we identified the clone 24E07 (NbME24E07) to be involved in nonhost disease resistance against the bacterial pathogen Pseudomonas syringae pv. tomato T1 $[43,44]$. The cDNA insert in 24E07 clone was sequenced. BLAST results of the sequence showed that it was homologous to $\mathrm{NbFDH1}$. Protein sequence analysis showed 
that $\mathrm{NbFDH1}$ is $96 \%$ identical to SIFDH1 and 80\% identical to AtFDH1 (Supplementary Figure 1). FDH1 is a single copy gene in both monocot and dicot plants.

Tobacco rattle virus (TRV)-based VIGS of NbFDH1 in N. benthamiana plants did not cause a visible phenotype regarding plant appearance. The downregulation of NbFDH1 was about 50\% in TRV::NbFDH1 inoculated plants when compared to TRV:00 (non-silenced control) inoculated plants (Supplementary Figure S2). NbFDH1-silenced and non-silenced control plants were inoculated with host and nonhost pathogens. Upon vacuum infiltration with the nonhost pathogen $P$. syringae pv. tomato $\mathrm{T} 1$ containing pDSK-GFPuv (Wang et al., 2007) at $1 \times 10^{4} \mathrm{CFU} / \mathrm{ml}$ concentration, the bacteria multiplied more in $\mathrm{NbFDH1-silenced} \mathrm{plants} \mathrm{when} \mathrm{compared} \mathrm{to} \mathrm{non-silenced} \mathrm{control} \mathrm{as} \mathrm{visualized}$ by green fluorescence under UV light (Figure 1A). In correlation with the increased nonhost bacterial multiplication, $\mathrm{NbFDH1}$ silenced plants also showed disease symptoms characterized by necrosis and chlorosis. In contrast, no disease symptoms were observed in the non-silenced control (Figure 1A). Further, the bacterial titer of nonhost pathogen $P$. syringae pv. tomato T1 was measured for three consecutive days after inoculation in both the NbFDH1-silenced and non-silenced control plants. Consistent with the disease

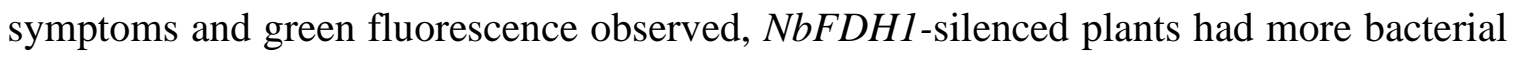
titer compared to non-silenced control (Figure 1B). In contrary to nonhost pathogen, multiplication of the host pathogen $P$. syringae pv. tabaci was not different in $N b F D H 1$ silenced plants when compared to non-silenced control (Figure 1C).

To check if $N b F D H 1$ has a role in nonhost HR, NbFDHI-silenced and nonsilenced control plants were syringe-infiltrated with a high level of inoculum $\left(1 \times 10^{6}\right.$ $\mathrm{CFU} / \mathrm{ml}$ ) of the nonhost pathogen $P$. syringae pv. tomato T1. Non-silenced control 
showed a typical nonhost HR after 24 hours post inoculation (hpi) whereas in $\mathrm{NbFDH1-}$ silenced lines, the HR was delayed until 48 hpi (Figure 1D). Taken together, these results suggest that $\mathrm{NbFDH1}$ plays a role in nonhost disease resistance against $P$. syringae pv. tomato T1 in N. benthamiana.

\section{Arabidopsis Atfdh1 mutants show increased susceptibility to host-pathogen and nonhost pathogens.}

To check if the role of $F D H 1$ in nonhost resistance is conserved in more than one plant species, two Arabidopsis T-DNA insertion mutants for AtFDH1 gene (SALK118548: Atfdhl-1 and SALK118644: Atfdhl-3) were identified in the Arabidopsis T-DNA insertion lines and were obtained from the Arabidopsis Biological Resource Center. Homozygous T-DNA insertion lines were generated by selfing and confirmed by PCR. When wild-type (Col-0) and Atfdhl mutants were flood inoculated [45, 46] with the nonhost pathogen $P$. syringae pv. tabaci, Atfdhl mutants, but not Col-0 showed disease symptoms characterized by chlorosis at 5-day post inoculation (dpi) (Figure 2A). In addition, Atfdhl mutants had higher bacterial titer (approximately 18-fold) when compared to Col-0 plants at $3 \mathrm{dpi}$ (Figure 2B). In response to infection with a host pathogen, $P$. syringae pv. maculicola, both Col-0 and the Atfdhl mutants showed similar

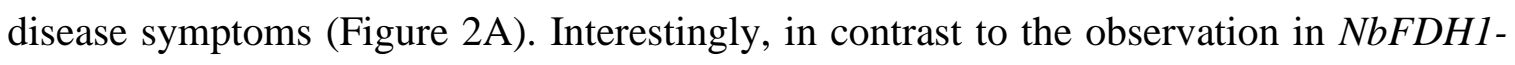
silenced $N$. benthamiana where the host pathogen titer didn't differ between silenced and control plants, Arabidopsis host pathogen, P. syringae pv. maculicola, grew slightly more in the Atfdh1 mutants when compared to Col-0 (Figure 2B). 
To check if AtFDH1 plays a role in gene-for-gene resistance, we infected Arabidopsis Col-0 plants that carry many resistance $(R)$ genes, including RPS4 with avirulent $P$. syringae pv. tomato DC3000 (AvrRPS4). After 3 dpi, P. syringae pv. tomato DC3000 (AvrRPS4) grew 3 logs in wild-type Col-0, but a significantly higher growth of bacteria was observed in the Atfdhl mutant lines (Figure 2C). This difference in growth was likely related to a deficiency in the production of ROS in the Atfdhl mutant lines. It has been known that the mutation of AtFDHI delays the production of ROS in response to P. syringae pv. tomato DC3000 (AvrRPM1) [23], and we also showed the delayed HR-

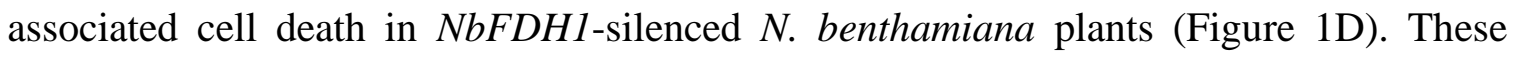
results suggest that $A t F D H 1$ confers plant defense through ROS dependent gene-for-gene resistance mechanisms.

\section{$A t F D H 1$ is induced in response to host and nonhost bacterial pathogens.}

In the publically available gene expression databases (TAIR), AtFDH1 is strongly expressed after $24 \mathrm{~h}$ of inoculation with the virulent pathogen $P$. syringae pv. tomato DC3000 and the avirulent pathogen $P$. syringae pv. tomato (AvrRPM1) (https://www.arabidopsis.org/servlets/TairObject?id=136173\&type=locus;

Supplementary Figure 3A). This agrees with the previous study of pepper mitochondrial FDH1 [23]. We also found that AtFDH1 gene expression is induced after host or nonhost pathogen inoculation (Supplementary Figure 3B). After inoculation with the virulent pathogen $P$. syringae pv. maculicola, $F D H 1$ expression was increased slightly (less than 0.5 -fold) in comparison with mock-inoculated plants. Inoculation with the nonhost pathogen $P$. syringae pv. tabaci caused a higher induction of FDHI and its level of 
expression was about 2-fold higher than in mock-inoculated plants (Supplementary Figure $3 \mathrm{~B}$ ). These results suggest that $\mathrm{FDH1}$ may play a greater role in nonhost disease resistance.

\section{Mutation of AtFDH1 alters the SA-mediated defense hormonal pathway to bacterial pathogens.}

As shown above, Atfdhl mutants are compromised in nonhost disease resistance, basal resistance, and gene-for-gene resistance. It was also found that the gene expression was induced in response to both host and nonhost pathogens (Supplementary Figure 3A). To examine if the resistance mechanism was related to a known common defense pathway such as salicylic acid (SA) and Jasmonic acid (JA), we conducted quantitative RT-PCR (RT-qPCR) for the gene expression of three representative genes related to SA pathway $(P A D 4, E D S 1$, and NPR1) and a gene related to JA pathway (PDF1.2) in wild-type Col-0 and the Atfdhl mutant without any pathogen inoculation and at 24 hpi with the host pathogen $P$. syringae pv. maculicola or the nonhost pathogen $P$. syringae pv. tabaci. Without any pathogen infection, $P A D 4, E D S 1$, and $N P R 1$, were not significantly different between Col-0 and Atfdh1-1, while the expression of JA marker gene PDF1.2 was remarkably increased in Atfdhl-1 (Supplementary Figure 3C). After 24 hpi with either pathogen in Col-0, the SA marker genes, PAD4 and EDS1, and JA marker gene, PDF1.2, were strongly induced, but the level of induction of these genes was significantly lower in the Atfdhl mutant against both host and nonhost pathogens, comparing to Col-0 (Figure 3). NPRl was significantly induced at 24 hpi with the host pathogen in wild-type Col-0 and significantly reduced (5-fold) in the Atfdhl mutant. NPRl was not significantly 
induced after inoculation with the nonhost pathogen in both mutant and wild-type lines. These results suggest that $A t F D H 1$ plays a role in plant defense responses via SA and JA mediated plant defense pathways.

\section{AtFDH1 localizes predominantly in mitochondria, but translocates to chloroplasts in response to abiotic and biotic stresses.}

Localization of FDH1 in mitochondria and/or chloroplast has been the subject of extensive debate [23, 26-29]. We cloned AtFDH1 to be expressed under its native promoter and fused it to the C-terminal of Green Fluorescent Protein $(G F P)$ gene and transiently expressed in $N$. benthamiana. The results showed that AtFDH1-GFP predominantly localizes to mitochondria (Supplementary Figure 4). We generated Arabidopsis stable lines expressing AtFDH1-GFP in Col-0, and the localization of AtFDH1-GFP in mitochondria was confirmed using the live cell mitochondrial stain MitoTracker (Figure 4). Upon challenging the plant with abiotic (wounding) and biotic (host [P. syringae pv. tomato DC3000] and nonhost [P. syringae pv. tomato T1] bacterial pathogens) stresses, AtFDH1-GFP signal was also found at the outer envelope membrane of chloroplasts in addition to mitochondria (Figure 4). Similar results were observed with another nonhost pathogen (P. syrinage pv. phaseolicola) (Supplementary Figure 5). The bacterial phytotoxin, coronatine, which is known to suppress SA-mediated plant defense, was used to examine if AtFDH1-GFP localizes to the chloroplast in the presence of coronatine. AtFDH1-GFP localization in chloroplast was not observed in the samples treated with coronatine (Figure 4). The expression of AtFDH1-GFP was remarkably increased after nonhost ( $P$. syringae pv. tomato T1 and $P$. syringae pv. phaseolicoa) and 
host (P. syringae pv. tomato DC3000) pathogen treatments than the expression in the detached leaf sample without pathogen challenge (Figure 4; Supplementary Figure 5).

Using the light-sheet microscope, the movement and co-localization of mitochondria with chloroplasts were observed after the inoculation of nonhost pathogen, $P$. syrinage pv. tomato T1. By performing time lapse image of FDH1 localization in the transgenic Arabidopsis line expressing FDH1-GFP, we found that mitochondrial specific FDH1 localization was highly motile after inoculation with a nonhost pathogen. As shown in the Figure 5, the majority of mitochondria localized FDH1 was in the vicinity of chloroplasts in outer-membrane regions (Figure 5). The arrow in each image (every 1min:30sec) indicates that the mitochondria localized FDH1 move to chloroplasts and attach there approximately for $1 \mathrm{~min}$, and later goes apart from the chloroplast. After this event, other mitochondria localized FDH1 translocate again to chloroplasts, and we observed the event of co-localization continuously during the $15 \mathrm{~min}$ of time lapse imaging. These results suggest that in response to nonhost pathogen FDH1 co-localizes to both mitochondria and chloroplast and the localization of FDH1 in chloroplast is transient.

To further investigate the specific localization of AtFDH1 in mitochondria and chloroplast upon host and nonhost pathogens, the protein of mitochondria and chloroplast were isolated separately from AtFDH1-GFP expressing plants and examined for the presence of AtFDH1 protein. Immunoblot analysis revealed that in total protein extract, AtFDH1-GFP accumulates in response to host and nonhost pathogens at 2 and $4 \mathrm{hpi}$, which agrees with the result of RT-qPCR (Figure 6 and Supplementary Figure 3). To validate the localization of AtFDH1, we isolated mitochondria and chloroplasts from AtFDH1-GFP expressing plants upon inoculation with host or nonhost pathogen. 
Mitochondria and chloroplast proteins were individually extracted and subjected to immunoblot analyses. AtFDH1-GFP protein was detected in mitochondria prior to pathogen infection, and the protein amount increased significantly after host or nonhost pathogen infection (Figure 6). By contrast, AtFDH1-GFP protein was not detected in the chloroplast protein extract prior to pathogen infection. Consistent with the cell biology data, AtFDH1-GFP was detected in the chloroplast protein extract after infection with host or nonhost pathogen infection (Figure 6). More AtFDH1 protein was detected in the chloroplast protein fraction after infection with nonhost pathogen when compared to host pathogen (Figure 6). These findings suggest that the localization of FDH1 in mitochondria may play a role for plant innate immunity against foliar bacterial pathogens, and FDH1 localization to chloroplasts may be important for nonhost disease resistance.

\section{Discussion}

FDH enzyme is found in various organisms, such as bacteria, yeast, and plants. This protein has been reported to function during various abiotic and biotic stress responses. Expression of $F D H$ is strongly induced during various abiotic and biotic stress responses such as pathogen, hypoxia, chilling, drought, dark, wounding and iron deficiency [22-24, 47]. There is only one study showing that FDH1 is involved in regulating plant cell death and defense responses against bacterial pathogens in pepper plants [23]. In this study, mitochondrial targeting of FDH1 plays an important role in PCD- and SA-dependent defense response, and silencing of $F D H 1$ attenuates resistance against $X$. campestris $\mathrm{pv}$. vesicatoria pathogen in pepper plants. Our study demonstrates that $F D H 1$ is required for plant innate immunity against both host and nonhost bacterial pathogens. Nonhost disease 
resistance is the most common form of plant defense against various pathogens $[5,8,48$, 49]. HR cell death are typical symptoms in response to ETI-triggered nonhost resistance in plants $[50,51]$. ROS produced in various cellular compartments, including chloroplasts, mitochondria, and peroxisomes have been proposed to act as signals for HR and PCD [52]. Chloroplasts are the main source of ROS during various environmental stresses, including plant-pathogen interactions [53]. In addition, ROS generated in mitochondria (mtROS) has been described in several studies to be an important factor in inducing HR cell death against plant pathogens [35]. Possibly both chloroplasts and mitochondria have a role in nonhost resistance against invading bacterial pathogens. In this study, we demonstrate that the protein encoded by a single $F D H 1$ gene in the nuclear genome are targeted to both mitochondria and chloroplasts in response to wounding and bacterial pathogens. Chloroplast localization of FDH1 was more abundant after inoculation with nonhost pathogens (Figure 4 and 5), thus suggesting a probable role of chloroplasts in nonhost disease resistance. A previous study has shown that chloroplast generated ROS is required for nonhost disease resistance in Arabidopsis [54]. In addition to nonhost resistance, we also show that $F D H 1$ plays a role in basal and gene-for-gene resistance in Arabidopsis. It is intriguing that the silencing of $\mathrm{NbFDHI}$ did not compromise basal resistance in $N$. benthamiana. Since the silencing of $N b F D H 1$ decreased $N b F D H 1$ transcripts by $\sim 50 \%$, we speculate that this is not sufficient to compromise basal resistance. By contrast, the complete knockout of AtFDH1 in Arabidopsis compromised basal resistance.

Our study identified a dual-targeting role for AtFDH1 during plant defense responses against bacterial pathogens. Dual targeting of FDH1 to mitochondria and 
chloroplasts may be necessary for effective signaling during plant defense against bacterial pathogens. In the Arabidopsis nuclear genome, approximately $20-25 \%$ of the genes encode proteins that are targeted to either mitochondria or chloroplasts [55]. It has been reported that some proteins target to both mitochondria and chloroplast, and might be more common than thought but their functions are not well understood, especially for plant disease resistance [56-60]. FDH1 has a putative mitochondrial signal peptide, although AtFDH1 has been reported to localize to either mitochondria or chloroplasts [28, 61-63]. Therefore, FDH1 localization in plants remains controversial. There was one study showing that the dual localization of AtFDH1 in both chloroplasts and mitochondria when AtFDH1 is overexpressed in transgenic Arabidopsis and tobacco plants [64]. It is also reported that the N-terminal region of AtFDH1 is predicted to contain the signal peptide region that could target it to chloroplasts as well as mitochondria [65]. This N-terminal sequence of AtFDH1 is quite different from potato, barley, and rice, suggesting AtFDH1 localizing in chloroplast could occur under certain conditions [63]. In our study, the localization of AtFDH1 in chloroplast was only detected under the conditions of wounding and pathogen stresses (Figure 4 and 5). As previously described, $F D H 1$ is highly induced under various stress conditions [63]. We speculate that the localization of FDH1 in chloroplast is too low and transient to be detected under non-stress conditions, and this causes controversy of the FDH1 localization in mitochondria or chloroplasts or both.

There are few reports that suggest FDH1 may have a role in biotic stress response in plants. As mention above, FDH1 has been shown to play a role in disease resistance in pepper against a bacterial pathogen (Choi et al., 2014). FDH1 and Calreticulin-3 
precursor (CRT3) directly interacts with the helicase domain of Cucumber mosaic virus (CMV) isolate-P1, suggesting that FDH1 has an important role in plant disease resistance [66]. CRT3 is localized in the endoplasmic reticulum (ER) lumen, and has been known to associate with abiotic stress response and plant immunity [67-69]. FDH1 directly interacts with RING-type ubiquitin ligase Keep on Going (KEG), which is localized in trans-golgi and early endosomes [70]. In Arabidopsis, the loss of function in KEG disrupts the secretion of the apoplastic defense proteins such as pathogenesis-related PR1, which indicates the involvement of KEG in plant immunity [71]. There are several reports describing the ROS-based signal transmission between mitochondria and chloroplasts [72-75]. Possibly, FDH1 protein could be transmitted to chloroplasts from mitochondria to interact with outer membrane proteins of chloroplasts and initiate a signal transduction pathway for the production of chloroplast-derived ROS.

In conclusion, we demonstrated a novel chloroplast-dependent pathway that regulates plant innate immunity, most likely through mitochondria-to-chloroplast integrated ROS signaling. Even though mitochondria is the main source of ROS, chloroplast also plays a role in producing ROS during stress responses in plants. However, the signal transduction between these organelles for coordinated production of ROS is not well understood. Characterization of molecular functions of FDH1-interactors in both mitochondria and chloroplasts would provide insight into the role of FDH1 in cross-talk between these organelles during biotic and abiotic stress responses.

\section{MATERIALS AND METHODS}

\section{Plant materials}


$N$. benthamiana plants were grown in 10-centimeter diameter round pots with BM7 soil (SUNGRO Horticulture Distribution, Inc., Bellevue WA) in the greenhouse using the condition described in the previous study [43]. Plants grown four weeks were used for virus-induced gene silencing (VIGS) experiments as described below. The ecotype of Arabidopsis thaliana, Col-0, was used as wild-type. Arabidopsis T-DNA knockout mutants for AtFDH1 gene (At5g14780), SALK_118644 and SALK_118548, were obtained from the Arabidopsis Biological Resource Center (Columbus, OH). To identify the homozygous knockout T-DNA mutant plants, seedlings grown from the SALK_118644 and SALK_118548 seeds and their progeny were harvested for PCRbased genotyping. Primers were designed from SALK T-DNA verification primer design (http://signal.salk.edu/tdnaprimers.2.html), and PCR was performed using REDExtractN-Amp ${ }^{\text {TM }}$ Tissue PCR Kit (Sigma-Aldrich, St. Louis, MO). All mutant plants were made homozygous for their respective T-DNA insertion, and seeds were harvested for further experiments. For seedling-flood inoculation [45], Arabidopsis plants were grown in 1/2 Murashige and Skoog (MS) agar medium plates at $25^{\circ} \mathrm{C}$ under short day condition $(12 \mathrm{~h}$ light).

\section{VIGS in Nicotiana benthamiana}

VIGS in N. benthamiana was performed as described [43]. In brief, Agrobacterium tumefaciens GV2260 containing TRV1, TRV2::00 and TRV2::NbFDH1 was grown overnight on LB medium containing antibiotics (rifampicin, 25; kanamycin, 50) at $28{ }^{\circ} \mathrm{C}$. Bacterial cells were harvested and re-suspended in induction medium (10 mM MES, pH 5.5; $200 \mu \mathrm{M}$ acetosyringone), and incubated at room temperature on an orbital shaker for 
5 hrs. Bacterial cultures containing TRV1 and TRV2 were mixed in equal ratios $\left(\mathrm{OD}_{600}=\right.$ 1) and infiltrated into $N$. benthamiana leaves using a $1 \mathrm{ml}$ needleless syringe. The infiltrated plants were maintained in a greenhouse and used for studies 15 to 21 days post-infiltration.

\section{Bacterial culture and inoculation}

Bacterial pathogens, Pseudomonas syringae pv. tabaci (Pstab), P. syringae pv. tomato T1 (Pst T1), and P. syringae pv. maculicola (Psm) were grown in King's B (KB) medium at $28{ }^{\circ} \mathrm{C}$ overnight. The bacterial culture was centrifuged at 5,000 rpm for $10 \mathrm{~min}$, and the cell pellet was re-suspended in $5 \mathrm{ml}$ sterilized distilled water. For the inoculation assays in $N$. benthamiana, bacterial vacuum infiltration was performed using the concentration of $1 \times 10^{4} \mathrm{CFU} / \mathrm{ml}$ for both $N$. benthamiana host (Pstab) and nonhost (Pst T1) pathogens. For the inoculation assays in Arabidopsis, host (Psm) and nonhost (Pstab) pathogens were used for the inoculation followed by the seedling flood-inoculation method $[45,46]$.

\section{Bacterial disease assay in N. benthamiana and Arabidopsis}

For disease assays in $N$. benthamiana, bacterial suspensions of host and nonhost pathogens $\left(1 \times 10^{5} \mathrm{CFU} / \mathrm{ml}\right)$ were vacuum-infiltrated in both silenced and control plants 2week after TRV infection. The fully expanded leaves were used for disease assays, and the inoculated plants were kept in a growth chamber at $20-22{ }^{\circ} \mathrm{C}$. The number of bacterial cells in leaf apoplast were measured 1,2, and 3 days after inoculation in N. benthamiana. The bacterial population at 0 day was estimated from leaves harvested $1 \mathrm{hr}$ after inoculation. Two leaf discs $\left(0.5 \mathrm{~cm}^{2}\right)$ from each leaf were collected in $1.5 \mathrm{ml}$ centrifuge tube containing 100 ul of sterilized distilled water. Samples were homogenized and 
plated on $\mathrm{KB}$ agar medium for measuring colony-forming units (CFU) per $\mathrm{cm}^{2}$ of leaf area. A total of three leaves were used for each experiment. To visualize bacterial colonization at infected sites in leaves, GFPuv-expressing $P$. syringae pv. tabaci and $P$. syringae pv. tomato T1 were vacuum infiltrated, and plants were examined under UV light 3 days after inoculation [76].

For disease assays in Arabidopsis, a flood inoculation method was used to infect Arabidopsis [45, 46]. Disease symptoms were observed 3 days after inoculation. For bacterial counting, leaves were surface-sterilized with $10 \%$ bleach for one min to eliminate epiphytic bacteria and then washed with sterile distilled water twice. The leaves were then homogenized in sterile distilled water, and serial dilutions were plated onto $\mathrm{KB}$ plates. Bacterial growth was evaluated in three independent experiments.

\section{Subcellular localization of FDH1 in N. benthamiana and Arabidopsis}

The full-length sequence of $A t F D H 1$ with native promoter was cloned into pMDC107 for GFP expression (AtFDH1-GFP). Stable Arabidopsis transgenic lines for the expression of AtFDH1-GFP were developed by floral dip transformation [77]. The subcellular location of AtFDH1-GFP in epidermal cells was determined under the confocal microscope.

To observe the localization of AtFDH1, Arabidopsis wild-type Col-0 and AtFDH1-GFP expressing (under the control of AtFDH1 promoter) transgenic plants in Col-0 were grown in $1 / 2 \mathrm{MS}$ media for four weeks, and AtFDH1-GFP expression in epidermal cells of Arabidopsis was visualized using a confocal microscope. The leaf tissues were floated with the bacterial suspension of host pathogen $P$. syringae pv. 
maculicola $\left(1 \times 10^{6} \mathrm{CFU} / \mathrm{ml}\right)$ and nonhost pathogen $P$. syringae pv. tabaci $\left(1 \times 10^{6}\right.$ $\mathrm{CFU} / \mathrm{ml}$ ). After one hour inoculation, the leaf tissues were washed with distilled water, and localization of FDH1-GFP was observed. For wounding stress, the adaxial epidermal peels from wild-type Col-0 and AtFDH1-GFP expressing transgenic plants were prepared in the MES buffer (10 mM, pH 6.5), and subcellular location of AtFDH1 was imaged under the confocal microscope.

\section{Isolation of chloroplast and mitochondria}

Arabidopsis leaves (10 g) were homogenized in $100 \mathrm{ml}$ of grinding buffer containing 50 mM HEPES (pH 8.0), $2 \mathrm{mM}$ EDTA, $1 \mathrm{mM} \mathrm{MgCl} 2,0.33 \mathrm{M}$ sorbitol, and $0.5 \mathrm{~g} / \mathrm{L} \mathrm{BSA}$ by using a motor-driven blender (WARING 51BL30, two $5 \mathrm{~s}$ bursts at maximum speed). The homogenate was filtered through 3 layers of miracloth (Sigma-Aldrich, St. Louis MO, USA). The cleared homogenate was centrifuged at $1,500 \mathrm{~g}$ for $10 \mathrm{~min}$ at $4{ }^{\circ} \mathrm{C}$. The supernatant was used for isolation of mitochondria, and the pellet was used for chloroplast extraction. For the isolation of chloroplast, the pellet was re-suspended in 3 $\mathrm{ml}$ of grinding buffer with a paint-brush. The chloroplast suspension was then loaded on top of linear Percoll gradient (2 ml of 70\% PBF-Percoll (v/v), $4 \mathrm{ml}$ of 50\% PBF-Percoll (v/v), and $4 \mathrm{ml}$ of $40 \%$ PBF-Percoll (v/v)) and centrifuged at $16,000 \mathrm{~g}$ for 20 min at $4{ }^{\circ} \mathrm{C}$. The lower green bands were collected for intact chloroplasts with glass pipette, washed twice with wash buffer (50 mM HEPES, pH 8.0, $2 \mathrm{mM}$ EDTA, $1 \mathrm{mM} \mathrm{MgCl}_{2}, 0.33 \mathrm{M}$ sorbitol), and centrifuged at $1,500 \mathrm{~g}$ for $10 \mathrm{~min}$ at $4{ }^{\circ} \mathrm{C}$. The supernatant was discarded and the washed chloroplast pellet was collected for chloroplast protein extraction. 
For the isolation of mitochondria, the supernatant was centrifuged at 3,000 $\mathrm{g}$ for 5 min at $4{ }^{\circ} \mathrm{C}$. The supernatant was transferred into a fresh centrifuge tube and centrifuged at $18,000 \mathrm{~g}$ for $20 \mathrm{~min}$ at $4{ }^{\circ} \mathrm{C}$. The greenish mitochondrial pellet was re-suspended carefully in $1 \mathrm{ml}$ wash buffer with a fine paint brush and adjusted the final volume to 4.8 ml. $1.2 \mathrm{ml}$ of $100 \%$ Percoll (Sigma-Aldrich, St. Louis, MO) was added and the total $6 \mathrm{ml}$ of mitochondria homogenate was then loaded on top of linear Percoll gradient $(5 \mathrm{ml}$ of $80 \%$ PBF-Percoll (v/v), $5 \mathrm{ml}$ of $33 \%$ PBF-Percoll). The mitochondria homogenate was centrifuged at 18,000 $\mathrm{g}$ for $1 \mathrm{hr}$ and greenish upper band was collected. Mitochondria was rinsed twice with $15 \mathrm{ml}$ wash buffer and centrifuged at $18,000 \mathrm{~g}$ for $20 \mathrm{~min}$ at $4{ }^{\circ} \mathrm{C}$. The supernatant was removed and the pellet was saved for mitochondria protein extraction.

\section{Protein extraction from chloroplast and mitochondria}

The mitochondrial and chloroplast proteins were isolated [78] in protein extraction buffer; $50 \mathrm{mM}$ Tris-HCL, $\mathrm{pH}$ 7.5, $75 \mathrm{mM} \mathrm{NaCl}, 0.2 \%$ Triton X-100, $5 \mathrm{mM}$ EDTA, 5 mM EGTA, 1 mM DTT, 100 uM MG132, 10 mM NaF, 2 mM Na2VO4, and $1 \%$ protease inhibitor cocktail (Sigma Aldrich, St. Louis, USA). The extracted proteins were quantified using Bradford method [79], and equal known concentrations were taken for the assay. Proteins were blotted on polyvinylidene fluoride (PVDF) membrane and Cox II antibody (Agrisera, Sweden, cat no. AS04 053A) for mitochondria and Rubisco or RBCL (Abiocode, CA, USA, cat.no. R3352-2) for chloroplast was used as markers to confirm the proteins. GFP antisera (Miltenyl Biotec, San Diego, CA, USA cat. no. 130091-833) was used to detect the FDH1 protein levels. The primary HRP-conjugated GFP 
antisera were diluted to 1:10,000 and visualized using ECL solution (GE Healthcare BioSciences, Pittsburgh, USA) and protein gel blots were imaged.

\section{Quantitative real-time PCR (RT-qPCR) analysis}

Total RNA was extracted from Arabidopsis leaves infiltrated with water (mock control), host pathogen ( $P$. syringae pv. maculicola) and nonhost pathogen ( $P$. syringae pv. tabaci), sampled at 0, 12 and $24 \mathrm{hrs}$ post-inoculation (hpi). RNA samples were treated with DNAseI (Ambion, Austin, TX) and used for cDNA synthesis using SuperScript III reverse transcriptase (Invitrogen, Grand Island, NY, USA). The cDNA was diluted to 1:20 and used for RT-qPCR using Power SYBR Green PCR master mix (Applied Biosystems, Foster City, CA, USA) with an ABI Prism 7900 HT sequence detection system (Applied Biosystems, Foster City, CA, USA). Arabidopsis Ubiquitin 5 (UBQ5) and Elongation factor $1 \alpha(E F 1 \alpha)$ were used as internal controls to ensure an equal amount of cDNA in individual reactions. Average Cycle Threshold $(\mathrm{Ct})$ values calculated using Sequence Detection Systems (version 2.2.2; Applied Biosystems) from duplicate samples and were used to determine the fold expression relative to controls. Two biological replicates of each sample and three technical replicates of each biological replicate were analyzed for RT-qPCR analysis.

\section{ACKNOWLEDGEMENTS}

This work was supported by the Noble Research Institute, LLC. We thank Dr. Jin Nakashima for assistance with cellular imaging and Dr. Elison Blancaflor for critical 
reading of the manuscript. The authors also thank all technical support and research assistance provided from Dr. Mysore Lab for this study.

\section{AUTHOR-RECOMMENDED INTERNET RESOURCE}

The Arabidopsis Information Resource (TAIR) AT5G14780 page:

https://www.arabidopsis.org/servlets/TairObject?id=136173\&type=locus

Bio-Analytic Resource for Plant Biology BAR ePlant database: http://bar.utoronto.ca/ eplant

\section{Figure Legends}

Figure 1. Virus-induced gene silencing of $\mathrm{NbFDH1}$ compromises nonhost resistance and elicitation of hypersensitive response in $N$. benthamiana. (A) GFP fluorescence associated with bacterial multiplication of nonhost bacteria in $\mathrm{NbFDH1}$ silenced $\mathrm{N}$. benthamiana leaves. Two weeks old $N$. benthamiana seedlings were inoculated with TRV1 + TRV::00 (control) or TRV1 + TRV::NbFDH1. Three weeks after TRV inoculation, nonhost bacterial pathogen $P$. syringae pv. tomato T1 expressing $p D S K$ $G F P_{u v}$ was vacuum infiltrated at $1 \times 10^{4} \mathrm{CFU} / \mathrm{ml}$ concentration. The photograph was taken under UV light 2 days post infection (dpi) as show in the upper panel. Visual disease symptoms were photographed at 5 dpi (lower panel). An increase in GFP fluorescence and disease symptoms were observed in TRV::NbFDH1 inoculated but not in the TRV::00 inoculated plants. (B and C) Bacterial titer of host and nonhost pathogens in both $N b F D H 1$-silenced and control plants. TRV inoculated plants (described above) were 
vacuum inoculated with host $(P$. syringae pv. tabaci) or nonhost ( $P$. syringae pv. tomato T1) bacterial pathogens $\left(1 \times 10^{4} \mathrm{CFU} / \mathrm{ml}\right)$, and bacteria were quantified by plating serial dilutions of leaf extracts. Asterisks indicate a significant difference from the control using Student's $t$ test $(\mathrm{P}<0.01)$. Bars represent mean, and error bars represent the standard deviation of three biological replicates (three technical replicates were used for each biological replicate). Each experiment showed similar results. (D) HR-related cell death in $\mathrm{NbFDH1}$-silenced and control plants. High concentration $\left(1 \times 10^{6} \mathrm{CFU} / \mathrm{ml}\right)$ of nonhost pathogen $P$. syringae pv. tomato T1 was infiltrated using a needless syringe into fully expanded $N$. benthamiana leaves, three weeks after TRV inoculation. Cell death due to nonhost HR was observed and photographed 24 and 48 hpi.

Figure 2. Arabidopsis Atfdh1 mutants are compromised in basal, nonhost, and genefor-gene resistance. (A) Disease symptoms of Atfdh1-1 mutant after inoculation with host or nonhost pathogens. Two-week-old Arabidopsis wild-type (Col-0) and Atfdh1-1 mutants grown in $1 / 2$ strength MS under short-day conditions ( 8 hrs of daylight) were flood-inoculated with host ( $P$. syringae pv. maculicola) or nonhost ( $P$. syringae pv. tabaci) pathogens at $3 \times 10^{6} \mathrm{CFU} / \mathrm{ml}$. Photographs were taken at four days post inoculation (dpi). (B) Bacterial titer of host and nonhost pathogens in Atfdhl mutants. Two-week-old Arabidopsis Col-0 and two Atfdhl mutant alleles (Atfdhl-1 and Atfdhl-3) were floodinoculated with host ( $P$. syringae pv. maculicola) or nonhost ( $P$. syringae pv. tabaci) pathogens at $1 \times 10^{5} \mathrm{CFU} / \mathrm{ml}$. Bacterial titers at 0 to 3 dpi were measured by taking leaf disks from four inoculated plants for each line. (C) Quantification of host bacterial multiplication during gene-for-gene resistance. Leaves from 6-week-old plants of Col-0 
and Atfdhl mutant alleles were syringe-infiltrated with avirulent (P. syringae pv. tomato DC3000 [AvrRps4]) bacterial strain at $2.8 \times 10^{5} \mathrm{CFU} / \mathrm{ml}$ concentration. Bacterial titer was measured at 0 and 3 dpi. Bars represent mean, and error bars represent standard deviation for four biological replicates with two independent experiments. The bacterial growth was similar between the experiments. Asterisks above bars represent statistically significant differences in comparison with wild-type plants using Student's $t$-test $(\mathrm{P}<$ $0.05)$.

Figure 3. Patterns of gene expression associated with SA-mediated defense signaling pathways in wild type (Col-0) and Atfdhl mutant (Atfdhl-1). The expression of SAmediated defense-related genes were examined after $24 \mathrm{hrs}$ (hpi) in response to host, $P$. syringae pv. maculicola, and nonhost pathogen, P. syringae pv. tabaci. The 4-week-old Seedlings flood-inoculated with the concentration of $1 \times 10^{5} \mathrm{CFU} / \mathrm{ml}$ bacterial suspension. Each column is the fold change of gene expression as determined by RT-qPCR at 24 hpi in pathogen-inoculated samples. The relative gene expression values normalized by Ubiquitin5 (UBQ5) and Elongation factor 1 alpha $(E F 1 \alpha)$ are represented as n-fold compared to the mock-treated plants. Fold changes are over the non-treated Col-0 or mutants. Asterisks above bars represent statistically significant differences in comparison with wild-type using Student's $t$-test $(\mathrm{P}<0.05)$. The gene expression was examined with four biological samples (three technical repeats for each sample). Psm24: 24 hours after the inoculation of $P$. syringae pv. maculicola, Pst24: 24 hours after inoculation of $P$. syringae pv. tabaci. 
Figure 4. Subcellular localization of AtFDH1 in Arabidopsis leaves. The expression and localization of AtFDH1-GFP was observed in detached (no stress) and peeled adaxial epidermal cells (wounding stress) from leaves of transgenic Arabidopsis lines expressing AtFDH1-GFP. The protein localization was also examined in detached leaf samples after the treatment of $P$. syringae pv. tomato DC3000 $\left(1 \times 10^{5} \mathrm{CFU} / \mathrm{ml}\right), P$. syringae pv. tomato $\mathrm{T} 1\left(1 \times 10^{5} \mathrm{CFU} / \mathrm{ml}\right)$, and coronatine $(50 \mathrm{uM})$ under a confocal microscope for wounding stress. MitoTracker red dye was used to stain mitochondria. Bars $=10 \mu \mathrm{m}$. For MitoTracker Red, a $561 \mathrm{~nm}$ excitation, 570-620 nm emission filter was used. Red channel shows chlorophyll auto fluorescence in chloroplasts of epidermal cells (yellow arrow). Green channel, shows the fluorescence signal of AtFDH-1GFP in mitochondria and outer membrane of chloroplast (white arrows). The pink arrows represent a merged signal of FDH1-GFP localization in mitochondria and chloroplast.

Figure 5. Time lapse imaging of co-localization of AtFDH1 in mitochondria and chloroplasts in response to nonhost pathogen. Detached leaves from transgenic Arabidopsis plants expressing AtFDH1-GFP driven by AtFDH1 promoter were treated with $P$. syrinage pv. tomato $\mathrm{T} 1\left(1 \times 10^{5} \mathrm{CFU} / \mathrm{ml}\right)$. AtFDH1 expression was monitored 40 min after the pathogen infection by using a light-sheet fluorescence microscope (Carl Zeiss, Germany). The images were observed for $15 \mathrm{~min}$ by time lapse imaging at 30 second intervals in Z-stack mode. For every $30 \mathrm{sec}$, the AtFDH1-GFP and chlorophyll fluorescence of chloroplast was captured and both live streaming videos were merged to generate time lapse video simultaneously. Images were taken from detached leaf samples 
60 min after treatment of $P$. syrinage pv. tomato T1. Times shown at bottom-right of each image are in minutes:seconds.

Figure 6. Accumulation of AtFDH1 protein in response to host or nonhost pathogens in mitochondria and chloroplasts. The 8-week-old Arabidopsis wild-type (Col-0) were flood-inoculated with the concentration of $1 \times 10^{5} \mathrm{CFU} / \mathrm{ml}$ bacterial suspension of $P$. syringae pv. maculicola (host) or $P$. syringae pv. tabaci (nonhost) pathogens. Leaf samples were collected at 0,2 , and 4 hpi for the protein extraction, and $3 \mu \mathrm{g}$ protein from mitochondria or chloroplast was used for the immunoblot assay. Because no AtFDH1GFP was visible in chloroplast samples with $3 \mu \mathrm{g}$ total protein, a total of $28 \mu \mathrm{g}$ was used. Rubisco: internal control for total protein (BPB stained gel), COXII: mitochondria marker protein detected using polyclonal COXII antisera (Agrisera), RBCL: chloroplast marker protein detected using polylonal Rbcl antisera (Abiocod).

\section{Supplementary Figure Legend}

Supplementary Figure 1. Sequence alignment of FDH1 protein from N. benthamiana (NbFDH1), tobacco (NtFDH1), tomato (SlFDH1), and Arabidopsis (AtFDH1). Sequence information was obtained from the public database; TAIR, NCBI GenBank, and Sol Genomics Network. The software MEGA-X [80] was used for sequence alignment. The colors amino acids were according to the default coloring schemes of ClustalX alignment, which depends on both residue type and the pattern of conservation within a column (http://www.clustal.org/clustal2/). 
Supplementary Figure 2. The expression of $\mathrm{NbFDH1}$ gene is reduced in $\mathrm{NbFDHI}$ silenced $N$. benthamiana plants. Two weeks old $N$. benthamiana seedlings were inoculated with TRV1 + TRV::00 (control) or TRV1 + TRV::NbFDH1. Three weeks after TRV inoculation, leaf samples from three different biological replicates for each construct were collected, and gene expression was measured by RT-qPCR. NbActin was used as internal control for normalization. Bars represent mean, and error bars represent standard deviation for three biological replicates (four technical replicates for each biological sample). Asterisk represents statistical significance that was determined using Student's $t$-test, $(\mathrm{P}<0.01)$.

Supplementary Figure 3. AtFDH1 is upregulated upon inoculation with host and nonhost pathogens in wild-type Col- 0 , and some defense-related genes are differentially expressed in Atfdhl mutant. (A) Gene expression patterns of AtFDHl against $P$. syringae bacterial pathogen in Arabidopsis. This data was obtained from Arabidopsis eFP Browser at bar.utoronto.ca [81]. (B) AtFDHI is induced by host and nonhost pathogen inoculations. Four-weeks-old Arabidopsis wild-type (Col-0) were flood-inoculated with host ( $P$. syringae pv. maculicola, Psm) or nonhost ( $P$. syringae pv. tabaci, Pstab) pathogens. The 24 hours after inoculation, leaves were harvested, total RNA was extracted, and subject to RT-qPCR using AtFDH1 specific primers. AtActin was used as an internal control for normalization. (C) Gene expression patterns of defense-related genes in wild-type and the Atfdhl mutant without any biotic or abiotic stresses. Leaves of four weeks old Arabidopsis wild-type (Col-0) and Atfdh1 mutant (fdh1-1) plants were 
collected, total RNA was isolated, and subject to RT-qPCR to measure the transcripts of $P A D 4, E D S 1, N P R 1$, and PDF1.2. Bars represent mean, and error bars represent standard deviation for three biological replicates (four technical replications for each biological replicate). Asterisks represent statistical significance as determined using Student's $t$-test, $(\mathrm{P}<0.01)$

Supplementary Figure 4. Subcellular localization of AtFDH1 in N. benthamiana. For Agrobacterium-mediated transient assay, a binary vector containing GFP gene fused to the C-terminal of AtFDH1 was transformed into the A. tumefaciens strain GV3101. The Agrobacterium suspension was $\left(5 \times 10^{7} \mathrm{CFU} / \mathrm{ml}\right)$ was infiltrated using a needle-less syringe into $N$. benthamiana leaves, and the green fluorescence representing AtFDH1 localization was observed 3 days after the agroinfiltration. Red channel (a $561 \mathrm{~nm}$ excitation, 570-620 nm emission filter) shows mitochondria stained with MitoTracker dye and green channel shows AtFDH1-GFP localization. Bars $=10 \mu \mathrm{m}$.

Supplementary Figure 5. Subcellular localization of AtFDH1 in Arabidopsis leaves. The expression and localization of AtFDH1-GFP was observed in detached (no stress) and peeled adaxial epidermal cells (pathogen stress) from leaves of transgenic Arabidopsis lines expressing AtFDH1-GFP in Col-0. The protein localization was also examined in detached leaf samples 1-hr after the treatment of $P$. syringae pv. tomato DC3000 $\left(1 \times 10^{5} \mathrm{CFU} / \mathrm{ml}\right)$ and $P$. syringae pv. phaseolicola $\left(1 \times 10^{5} \mathrm{CFU} / \mathrm{ml}\right)$. Red channel (a $561 \mathrm{~nm}$ excitation, 570-620 nm emission filter), showing chloroplast; green channel showing AtFDH1-GFP. Bars $=10 \mu \mathrm{m}$. 


\section{LITERATURE CITED}

1. Niks, R. E.; Marcel, T. C., Nonhost and basal resistance: how to explain specificity? The New phytologist 2009, 182, (4), 817-28.

2. Truman, W.; de Zabala, M. T.; Grant, M., Type III effectors orchestrate a complex interplay between transcriptional networks to modify basal defence responses during pathogenesis and resistance. The Plant journal : for cell and molecular biology 2006, 46, (1), 14-33.

3. Andersen, E. J.; Ali, S.; Byamukama, E.; Yen, Y.; Nepal, M. P., Disease Resistance Mechanisms in Plants. Genes (Basel) 2018, 9, (7), 339.

4. Gill, U. S.; Lee, S.; Mysore, K. S., Host versus nonhost resistance: distinct wars with similar arsenals. Phytopathology 2015, 105, (5), 580-7.

5. Senthil-Kumar, M.; Mysore, K. S., Nonhost resistance against bacterial pathogens: retrospectives and prospects. Annu Rev Phytopathol 2013, 51, 407-27.

6. Aghnoum, R.; Marcel, T. C.; Johrde, A.; Pecchioni, N.; Schweizer, P.; Niks, R. E., Basal host resistance of barley to powdery mildew: connecting quantitative trait Loci and candidate genes. Molecular plant-microbe interactions : MPMI 2010, 23, (1), 91-102.

7. Fonseca, J. P.; Mysore, K. S., Genes involved in nonhost disease resistance as a key to engineer durable resistance in crops. Plant science : an international journal of experimental plant biology 2019, 279, 108-116.

8. Lee, S.; Whitaker, V. M.; Hutton, S. F., Mini Review: Potential Applications of Non-host Resistance for Crop Improvement. Frontiers in plant science 2016, 7, 997-997.

9. Romero, C. C. T.; Vermeulen, J. P.; Vels, A.; Himmelbach, A.; Mascher, M.; Niks, R. E., Mapping resistance to powdery mildew in barley reveals a largeeffect nonhost resistance QTL. Theoretical and Applied Genetics 2018, 131, (5), 1031-1045.

10. Mysore, K. S.; Ryu, C. M., Nonhost resistance: how much do we know? Trends in plant science 2004, 9, (2), 97-104.

11. Senthil - Kumar, M.; Wang, M.; Chang, J.; Ramegowda, V.; Del Pozo, O.; Liu, Y.; Doraiswamy, V.; Lee, H. K.; Ryu, C. M.; Wang, K., Virus - induced gene silencing database for phenomics and functional genomics in Nicotiana benthamiana. Plant direct 2018, 2, (4), e00055.

12. Li, B.; Meng, X.; Shan, L.; He, P., Transcriptional Regulation of PatternTriggered Immunity in Plants. Cell host \& microbe 2016, 19, (5), 641-650.

13. Bigeard, J.; Colcombet, J.; Hirt, H., Signaling mechanisms in pattern-triggered immunity (PTI). Molecular plant 2015, 8, (4), 521-39.

14. Melotto, M.; Underwood, W.; Koczan, J.; Nomura, K.; He, S. Y., Plant stomata function in innate immunity against bacterial invasion. Cell 2006, 126, (5), 96980 . 
15. Uppalapati, S. R.; Ayoubi, P.; Weng, H.; Palmer, D. A.; Mitchell, R. E.; Jones, W.; Bender, C. L., The phytotoxin coronatine and methyl jasmonate impact multiple phytohormone pathways in tomato. The Plant journal : for cell and molecular biology 2005, 42, (2), 201-17.

16. Katsir, L.; Schilmiller, A. L.; Staswick, P. E.; He, S. Y.; Howe, G. A., COI1 is a critical component of a receptor for jasmonate and the bacterial virulence factor coronatine. Proceedings of the National Academy of Sciences of the United States of America 2008, 105, (19), 7100-5.

17. Geng, X.; Cheng, J.; Gangadharan, A.; Mackey, D., The Coronatine Toxin of $<\mathrm{em}>$ Pseudomonas syringae</em> Is a Multifunctional Suppressor of $<\mathrm{em}>$ Arabidopsis</em> Defense. The Plant cell 2012, 24, (11), 4763-4774.

18. Lee, S.; Ishiga, Y.; Clermont, K.; Mysore, K. S., Coronatine inhibits stomatal closure and delays hypersensitive response cell death induced by nonhost bacterial pathogens. PeerJ 2013, 1, e34.

19. Spoel, S. H.; Dong, X., How do plants achieve immunity? Defence without specialized immune cells. Nature Reviews Immunology 2012, 12, (2), 89-100.

20. Gassmann, W.; Bhattacharjee, S., Effector-triggered immunity signaling: from gene-for-gene pathways to protein-protein interaction networks. Molecular plantmicrobe interactions : MPMI 2012, 25, (7), 862-8.

21. Cui, H.; Tsuda, K.; Parker, J. E., Effector-Triggered Immunity: From Pathogen Perception to Robust Defense. Annual review of plant biology 2015, 66, (1), 487511.

22. Hourton-Cabassa, C.; Ambard-Bretteville, F.; Moreau, F.; Davy de Virville, J.; Remy, R.; Francs-Small, C. C., Stress Induction of Mitochondrial Formate Dehydrogenase in Potato Leaves. Plant physiology 1998, 116, (2), 627-35.

23. Choi, D. S.; Kim, N. H.; Hwang, B. K., Pepper mitochondrial FORMATE DEHYDROGENASE1 regulates cell death and defense responses against bacterial pathogens. Plant physiology 2014, 166, (3), 1298-1311.

24. Lou, H. Q.; Gong, Y. L.; Fan, W.; Xu, J. M.; Liu, Y.; Cao, M. J.; Wang, M.-H.; Yang, J. L.; Zheng, S. J., A Formate Dehydrogenase Confers Tolerance to Aluminum and Low pH. Plant physiology 2016, 171, (1), 294-305.

25. Ambard-Bretteville, F.; Sorin, C.; Rébeillé, F.; Hourton-Cabassa, C.; Colas des Francs-Small, C., Repression of formate dehydrogenase in Solanum tuberosum increases steady-state levels of formate and accelerates the accumulation of proline in response to osmotic stress. Plant molecular biology 2003, 52, (6), 11531168.

26. Oliver, D. J., Formate Oxidation and Oxygen Reduction by Leaf Mitochondria. Plant physiology 1981, 68, (3), 703.

27. des Francs-Small, C. C.; Ambard-Bretteville, F.; Small, I. D.; Remy, R., Identification of a Major Soluble Protein in Mitochondria from Nonphotosynthetic Tissues as NAD-Dependent Formate Dehydrogenase. Plant physiology 1993, 102, (4), 1171.

28. Wang, R.; Zeng, Z.; Guo, H.; Tan, H.; Liu, A.; Zhao, Y.; Chen, L., Overexpression of the Arabidopsis formate dehydrogenase in chloroplasts enhances formaldehyde uptake and metabolism in transgenic tobacco leaves. Planta 2018, $247,(2), 339-354$. 
29. Kebeish, R.; Aboelmy, M.; El-Naggar, A.; El-Ayouty, Y.; Peterhansel, C., Simultaneous overexpression of cyanidase and formate dehydrogenase in Arabidopsis thaliana chloroplasts enhanced cyanide metabolism and cyanide tolerance. Environmental and Experimental Botany 2015, 110, 19-26.

30. Bobik, K.; Burch-Smith, T. M., Chloroplast signaling within, between and beyond cells. Frontiers in plant science 2015, 6, 781-781.

31. Mukhtar, M. S.; McCormack, M. E.; Argueso, C. T.; Pajerowska-Mukhtar, K. M., Pathogen tactics to manipulate plant cell death. Current Biology 2016, 26, (13), R608-R619.

32. de Torres Zabala, M.; Littlejohn, G.; Jayaraman, S.; Studholme, D.; Bailey, T.; Lawson, T.; Tillich, M.; Licht, D.; Bölter, B.; Delfino, L.; Truman, W.; Mansfield, J.; Smirnoff, N.; Grant, M., Chloroplasts play a central role in plant defence and are targeted by pathogen effectors. Nature Plants 2015, 1, (6), 15074.

33. Serrano, I.; Audran, C.; Rivas, S., Chloroplasts at work during plant innate immunity. Journal of experimental botany 2016, 67, (13), 3845-3854.

34. Colombatti, F.; Gonzalez, D. H.; Welchen, E., Plant mitochondria under pathogen attack: a sigh of relief or a last breath? Mitochondrion 2014, 19 Pt B, 238-44.

35. Huang, S.; Van Aken, O.; Schwarzländer, M.; Belt, K.; Millar, A. H., The roles of mitochondrial reactive oxygen species in cellular signaling and stress response in plants. Plant physiology 2016, 171, (3), 1551-1559.

36. Frederick, S. E.; Newcomb, E. H., Microbody-like organelles in leaf cells. Science 1969, 163, (3873), 1353-1355.

37. Takagi, S., Actin-based photo-orientation movement of chloroplasts in plant cells. Journal of Experimental Biology 2003, 206, (12), 1963-1969.

38. Logan, D. C.; Leaver, C. J., Mitochondria - targeted GFP highlights the heterogeneity of mitochondrial shape, size and movement within living plant cells. Journal of experimental botany 2000, 51, (346), 865-871.

39. Raghavendra, A. S.; Padmasree, K., Beneficial interactions of mitochondrial metabolism with photosynthetic carbon assimilation. Trends in plant science 2003, 8, (11), 546-553.

40. Noctor, G.; De Paepe, R.; Foyer, C. H., Mitochondrial redox biology and homeostasis in plants. Trends in plant science 2007, 12, (3), 125-134.

41. Noguchi, K.; Yoshida, K., Interaction between photosynthesis and respiration in illuminated leaves. Mitochondrion 2008, 8, (1), 87-99.

42. Islam, M. S.; Takagi, S., Co-localization of mitochondria with chloroplasts is a light-dependent reversible response. Plant signaling \& behavior 2010, 5, (2), 146147.

43. Senthil-Kumar, M.; Mysore, K. S., Tobacco rattle virus-based virus-induced gene silencing in Nicotiana benthamiana. Nature protocols 2014, 9, (7), 1549-62.

44. Senthil-Kumar, M.; Lee, H. K.; Mysore, K. S., VIGS-mediated forward genetics screening for identification of genes involved in nonhost resistance. Journal of visualized experiments : JoVE 2013, (78), e51033.

45. Ishiga, Y.; Ishiga, T.; Uppalapati, S. R.; Mysore, K. S., Arabidopsis seedling flood-inoculation technique: a rapid and reliable assay for studying plant-bacterial interactions. Plant Methods 2011, 7, 32. 
46. Ishiga, Y.; Ishiga, T.; Ichinose, Y.; Mysore, K. S., Pseudomonas syringae Floodinoculation Method in Arabidopsis. Bio-protocol 2017, 7, (2), e2106.

47. Hourton-Cabassa, C.; Ambard-Bretteville, F.; Moreau, F.; de Virville, J. D.; Rémy, R.; Colas des Francs-Small, C., Stress Induction of Mitochondrial Formate Dehydrogenase in Potato Leaves. Plant physiology 1998, 116, (2), 627-635.

48. Lee, H.-A.; Lee, H.-Y.; Seo, E.; Lee, J.; Kim, S.-B.; Oh, S.; Choi, E.; Choi, E.; Lee, S. E.; Choi, D., Current Understandings of Plant Nonhost Resistance. Molecular Plant-Microbe Interactions ${ }^{\circledR}$ 2016, 30, (1), 5-15.

49. Strugala, R.; Delventhal, R.; Schaffrath, U., An organ-specific view on non-host resistance. Frontiers in plant science 2015, 6, (526).

50. Tsuda, K.; Katagiri, F., Comparing signaling mechanisms engaged in patterntriggered and effector-triggered immunity. Current opinion in plant biology 2010, $13,(4), 459-465$.

51. Dodds, P. N.; Rathjen, J. P., Plant immunity: towards an integrated view of plantpathogen interactions. Nature Reviews Genetics 2010, 11, (8), 539-548.

52. Nomura, H.; Komori, T.; Uemura, S.; Kanda, Y.; Shimotani, K.; Nakai, K.; Furuichi, T.; Takebayashi, K.; Sugimoto, T.; Sano, S.; Suwastika, I. N.; Fukusaki, E.; Yoshioka, H.; Nakahira, Y.; Shiina, T., Chloroplast-mediated activation of plant immune signalling in Arabidopsis. Nature communications 2012, 3, (1), 926.

53. Padmanabhan, M. S.; Dinesh-Kumar, S. P., All Hands on Deck-The Role of Chloroplasts, Endoplasmic Reticulum, and the Nucleus in Driving Plant Innate Immunity. Molecular Plant-Microbe Interactions ${ }^{\circledR}$ 2010, 23, (11), 1368-1380.

54. Ishiga, Y.; Ishiga, T.; Ikeda, Y.; Matsuura, T.; Mysore, K. S., NADPH-dependent thioredoxin reductase $\mathrm{C}$ plays a role in nonhost disease resistance against Pseudomonas syringae pathogens by regulating chloroplast-generated reactive oxygen species. PeerJ 2016, 4, e1938-e1938.

55. Initiative, A. G., Analysis of the genome sequence of the flowering plant Arabidopsis thaliana. Nature 2000, 408, (6814), 796.

56. Peeters, N.; Small, I., Dual targeting to mitochondria and chloroplasts. Biochimica et Biophysica Acta (BBA) - Molecular Cell Research 2001, 1541, (1), 54-63.

57. Robinson, C., Targeting of proteins to chloroplasts and mitochondria. In Plant Genetic Engineering, Grierson, D., Ed. Springer Netherlands: Dordrecht, 1991; pp 179-198.

58. Berglund, A. K.; Spånning, E.; Biverståhl, H.; Maddalo, G.; Tellgren-Roth, C.; Mäler, L.; Glaser, E., Dual targeting to mitochondria and chloroplasts: characterization of Thr-tRNA synthetase targeting peptide. Molecular plant 2009, 2, (6), 1298-309.

59. Lee, J.; Kim, D. H.; Hwang, I., Specific targeting of proteins to outer envelope membranes of endosymbiotic organelles, chloroplasts, and mitochondria. Frontiers in plant science 2014, 5, (173).

60. Schleiff, E.; Becker, T., Common ground for protein translocation: access control for mitochondria and chloroplasts. Nature Reviews Molecular Cell Biology 2011, $12,(1), 48-59$.

61. Ambard-Bretteville, F.; Small, I.; Grandjean, O.; des Francs-Small, C. C., Discrete mutations in the presequence of potato formate dehydrogenase inhibit the 
in vivo targeting of GFP fusions into mitochondria. Biochemical and biophysical research communications $\mathbf{2 0 0 3}, 311$, (4), 966-971.

62. Jänsch, L.; Kruft, V.; Schmitz, U. K.; Braun, H. P., New insights into the composition, molecular mass and stoichiometry of the protein complexes of plant mitochondria. The Plant Journal 1996, 9, (3), 357-368.

63. Alekseeva, A. A.; Savin, S. S.; Tishkov, V. I., NAD (+) -dependent Formate Dehydrogenase from Plants. Acta Naturae 2011, 3, (4), 38-54.

64. Herman, P. L.; Ramberg, H.; Baack, R. D.; Markwell, J.; Osterman, J. C., Formate dehydrogenase in Arabidopsis thaliana: overexpression and subcellular localization in leaves. Plant Science 2002, 163, (6), 1137-1145.

65. Olson, B. J. S. C.; Skavdahl, M.; Ramberg, H.; Osterman, J. C.; Markwell, J., Formate dehydrogenase in Arabidopsis thaliana: characterization and possible targeting to the chloroplast. Plant Science 2000, 159, (2), 205-212.

66. Choi, Y.; Kang, M.-Y.; Lee, J.-H.; Kang, W.-H.; Hwang, J.; Kwon, J.-K.; Kang, B.-C., Isolation and Characterization of Pepper Genes Interacting with the CMVP1 Helicase Domain. PloS one 2016, 11, (1), e0146320.

67. Jia, X.-Y.; Xu, C.-Y.; Jing, R.-L.; Li, R.-Z.; Mao, X.-G.; Wang, J.-P.; Chang, X.P., Molecular cloning and characterization of wheat calreticulin (CRT) gene involved in drought-stressed responses. Journal of experimental botany 2008, 59, (4), 739-751.

68. Li, J.; Zhao-Hui, C.; Batoux, M.; Nekrasov, V.; Roux, M.; Chinchilla, D.; Zipfel, C.; Jones, J. D., Specific ER quality control components required for biogenesis of the plant innate immune receptor EFR. Proceedings of the National Academy of Sciences 2009, 106, (37), 15973-15978.

69. Qiu, Y.; Xi, J.; Du, L.; Roje, S.; Poovaiah, B., A dual regulatory role of Arabidopsis calreticulin - 2 in plant innate immunity. The Plant Journal 2012, 69, (3), 489-500.

70. McNeilly, D.; Schofield, A.; Stone, S. L., Degradation of the stress-responsive enzyme formate dehydrogenase by the RING-type E3 ligase Keep on Going and the ubiquitin $26 \mathrm{~S}$ proteasome system. Plant molecular biology 2018, 96, (3), 265278.

71. Gu, Y.; Innes, R. W., The KEEP ON GOING protein of Arabidopsis regulates intracellular protein trafficking and is degraded during fungal infection. The Plant cell 2012, 24, (11), 4717-4730.

72. Shapiguzov, A.; Vainonen, J. P.; Hunter, K.; Tossavainen, H.; Tiwari, A.; Järvi, S.; Hellman, M.; Aarabi, F.; Alseekh, S.; Wybouw, B.; Van Der Kelen, K.; Nikkanen, L.; Krasensky-Wrzaczek, J.; Sipari, N.; Keinänen, M.; Tyystjärvi, E.; Rintamäki, E.; De Rybel, B.; Salojärvi, J.; Van Breusegem, F.; Fernie, A. R.; Brosché, M.; Permi, P.; Aro, E.-M.; Wrzaczek, M.; Kangasjärvi, J., Arabidopsis RCD1 coordinates chloroplast and mitochondrial functions through interaction with ANAC transcription factors. eLife 2019, 8, e43284.

73. Zhao, Y.; Luo, L.; Xu, J.; Xin, P.; Guo, H.; Wu, J.; Bai, L.; Wang, G.; Chu, J.; Zuo, J.; Yu, H.; Huang, X.; Li, J., Malate transported from chloroplast to mitochondrion triggers production of ROS and PCD in Arabidopsis thaliana. Cell Research 2018, 28, (4), 448-461. 
74. Shapiguzov, A.; Vainonen, J. P.; Wrzaczek, M.; Kangasjärvi, J., ROS-talk - how the apoplast, the chloroplast, and the nucleus get the message through. Frontiers in plant science 2012, 3, 292-292.

75. Zottini, M., Cross-Talk of Mitochondria and Chloroplasts. In 2013; Vol. 36, pp 481-502.

76. Wang, K.; Kang, L.; Anand, A.; Lazarovits, G.; Mysore, K. S., Monitoring in planta bacterial infection at both cellular and whole-plant levels using the green fluorescent protein variant GFPuv. The New phytologist 2007, 174, (1), 212-23.

77. Davis, A. M.; Hall, A.; Millar, A. J.; Darrah, C.; Davis, S. J., Protocol: Streamlined sub-protocols for floral-dip transformation and selection of transformants in Arabidopsis thaliana. Plant Methods 2009, 5, (1), 3.

78. Murcha, M. W.; Whelan, J., Isolation of Intact Mitochondria from the Model Plant Species Arabidopsis thaliana and Oryza sativa. In Plant Mitochondria: Methods and Protocols, Whelan, J.; Murcha, M. W., Eds. Springer New York: New York, NY, 2015; pp 1-12.

79. Bradford, M. M., A rapid and sensitive method for the quantitation of microgram quantities of protein utilizing the principle of protein-dye binding. Analytical Biochemistry 1976, 72, (1), 248-254.

80. Kumar, S.; Stecher, G.; Li, M.; Knyaz, C.; Tamura, K., MEGA X: Molecular Evolutionary Genetics Analysis across Computing Platforms. Molecular biology and evolution 2018, 35, (6), 1547-1549.

81. Winter, D.; Vinegar, B.; Nahal, H.; Ammar, R.; Wilson, G. V.; Provart, N. J., An "Electronic Fluorescent Pictograph" Browser for Exploring and Analyzing LargeScale Biological Data Sets. PloS one 2007, 2, (8), e718. 


\section{A}
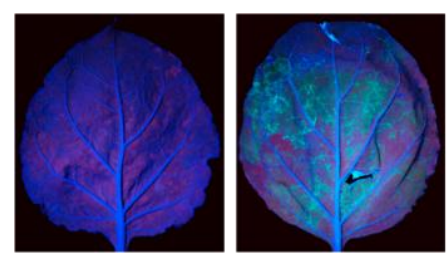

2 dpi
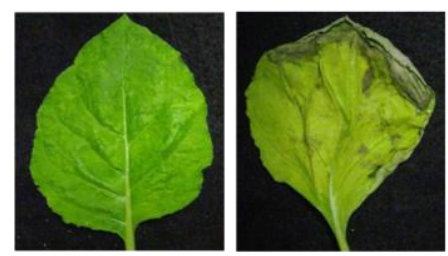

$5 \mathrm{dpi}$

TRV::00

TRV::NbFDH1

B

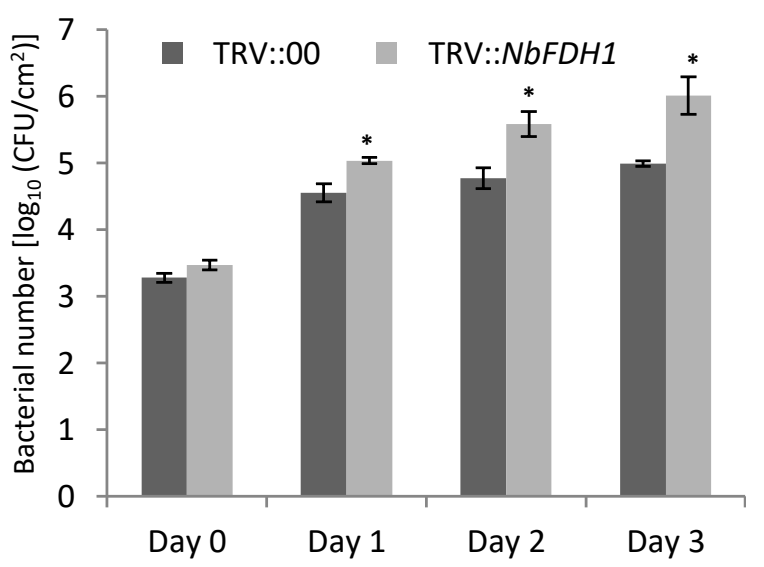

D

TRV::00

TRV::NbFDH1
C

P. syringae pv. tabaci

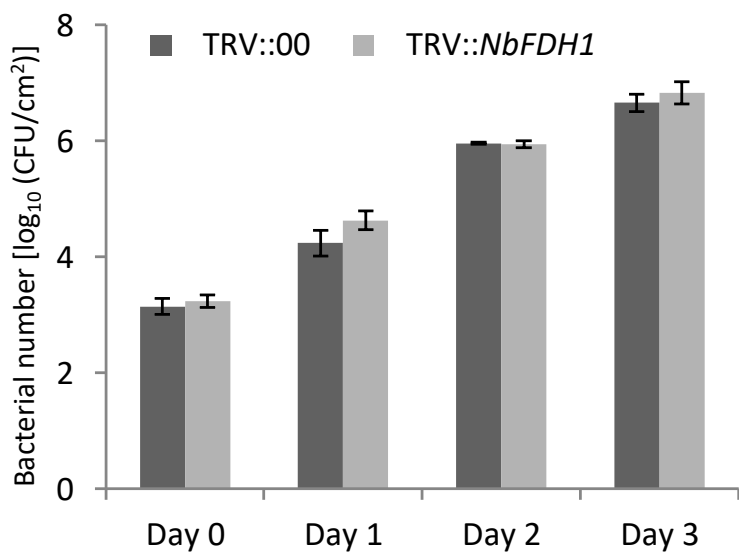

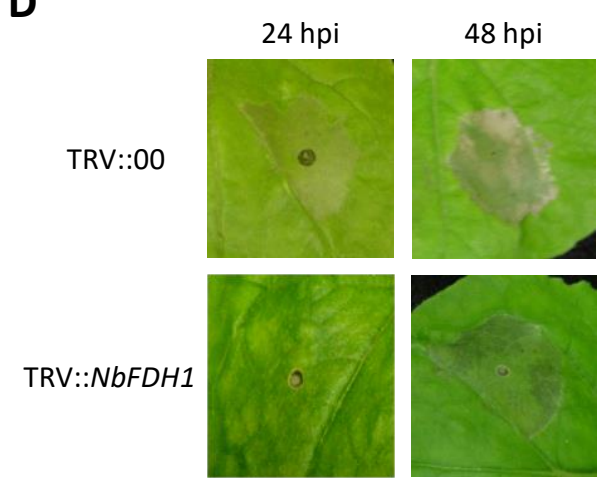




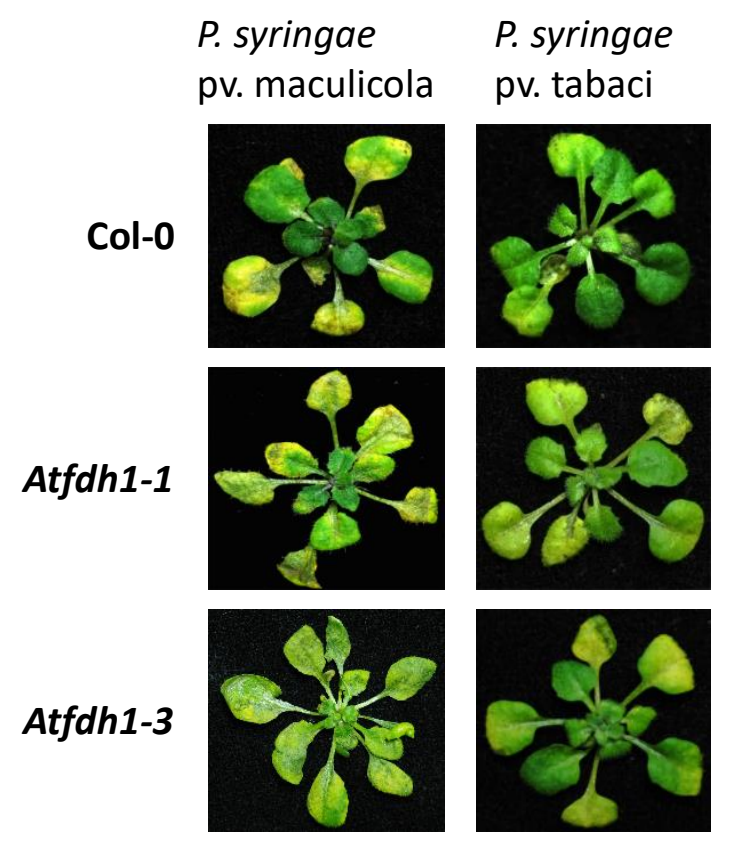

B

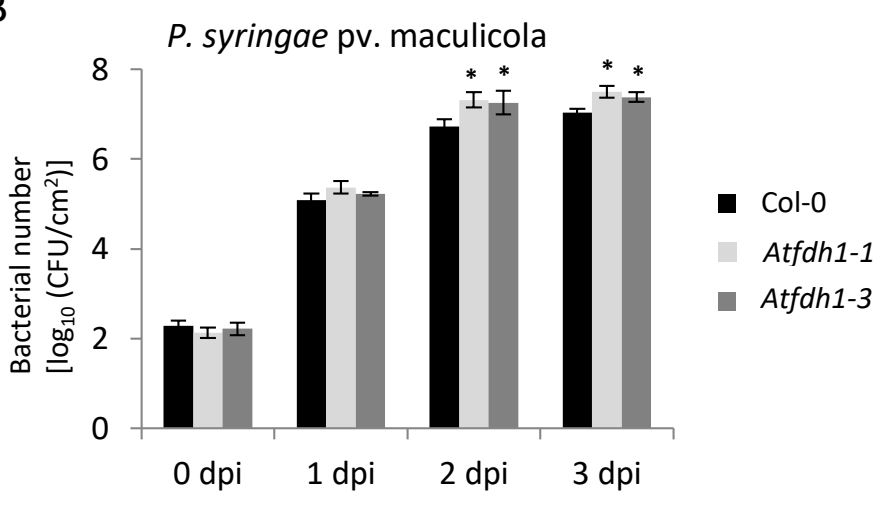

Time after inoculation

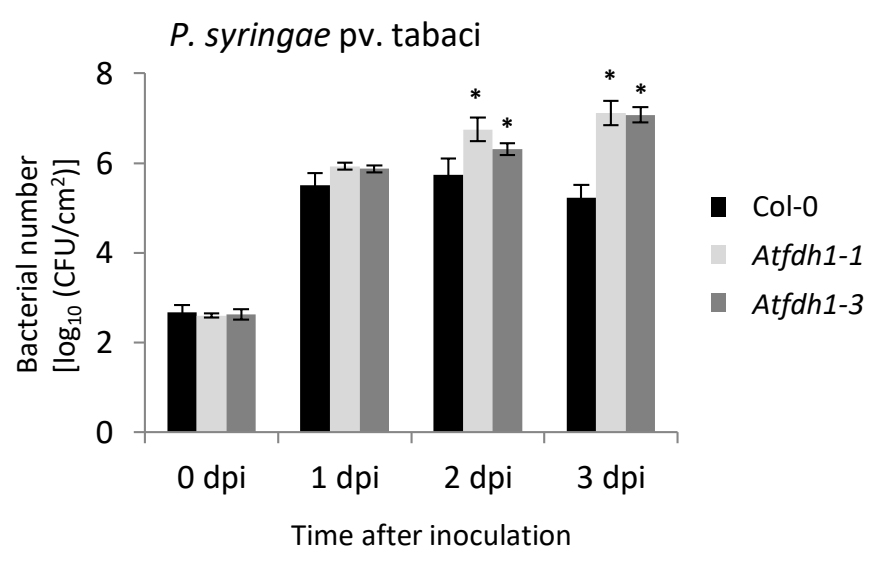

C

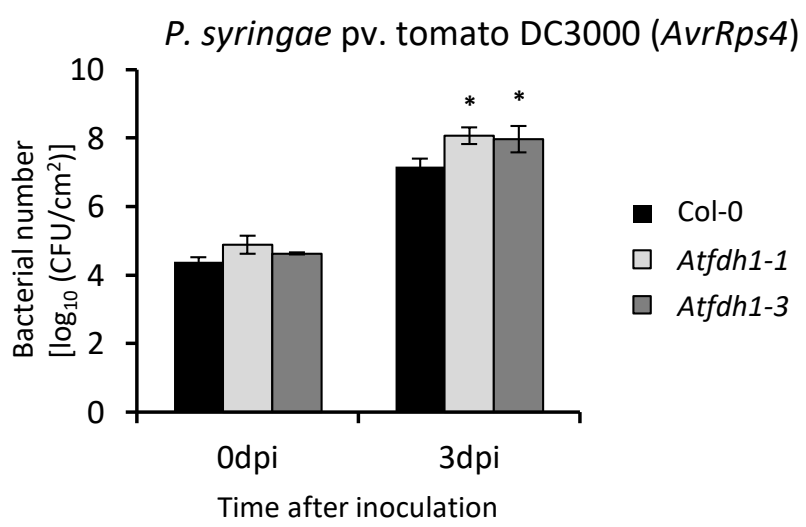



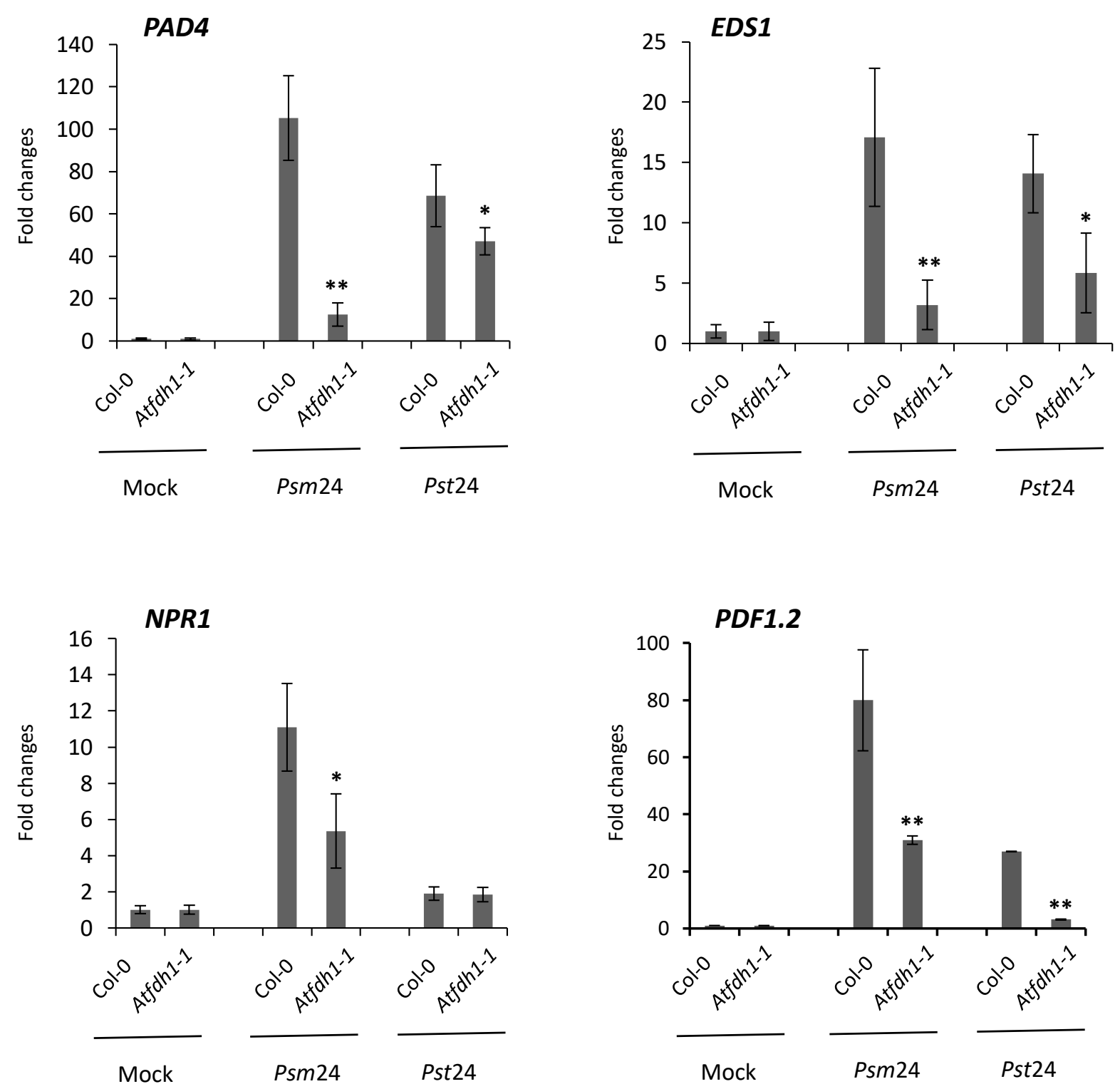


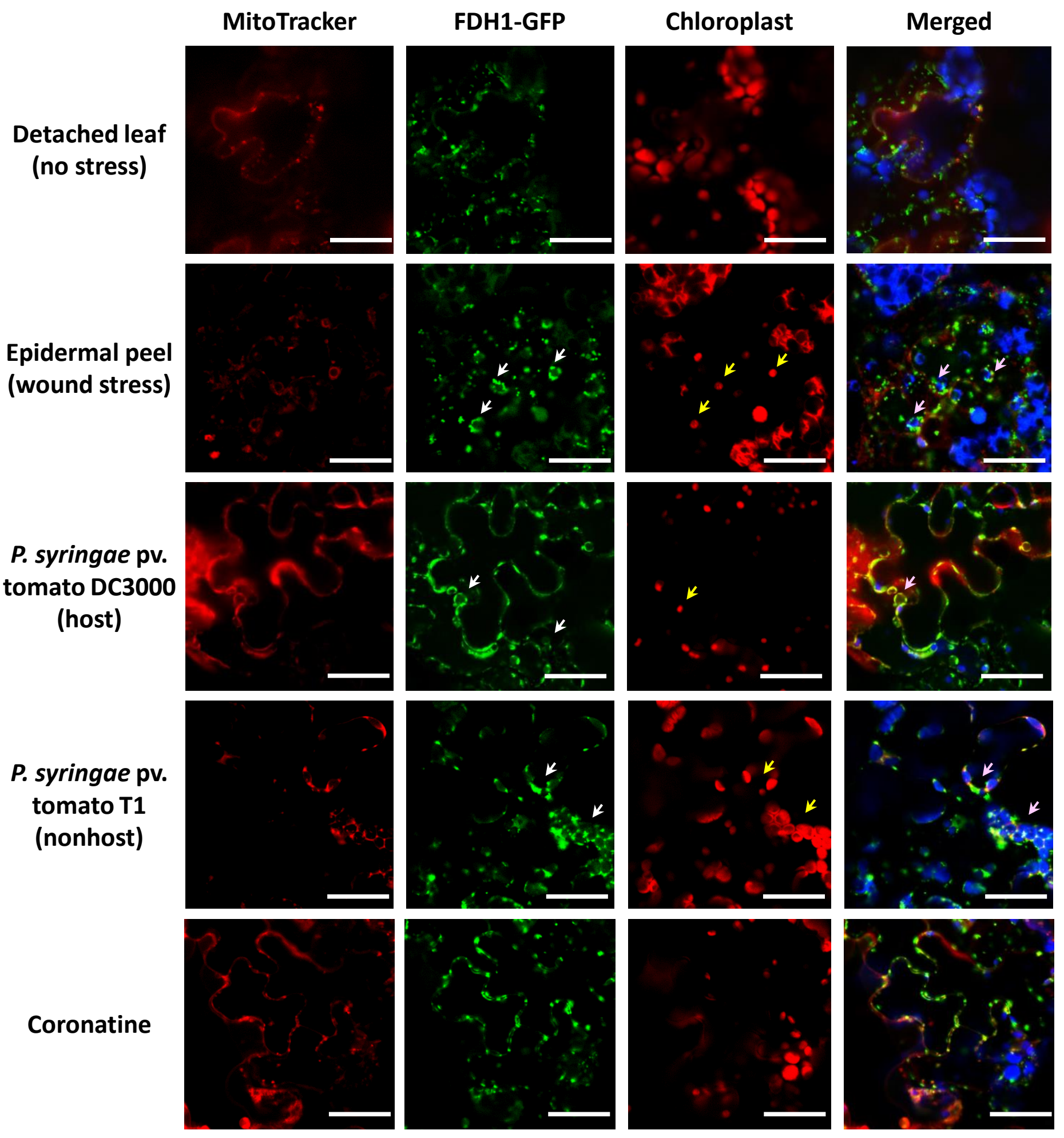




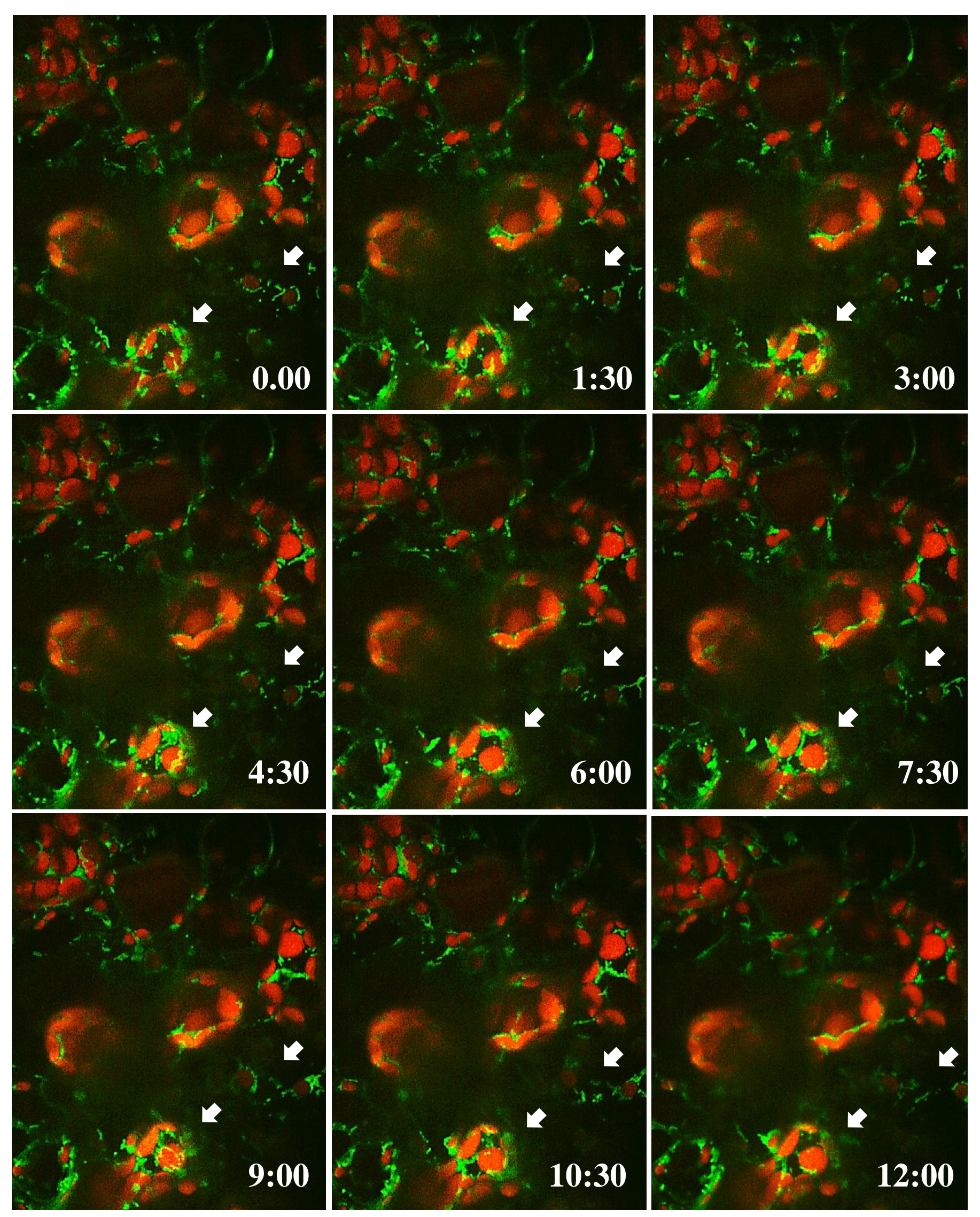




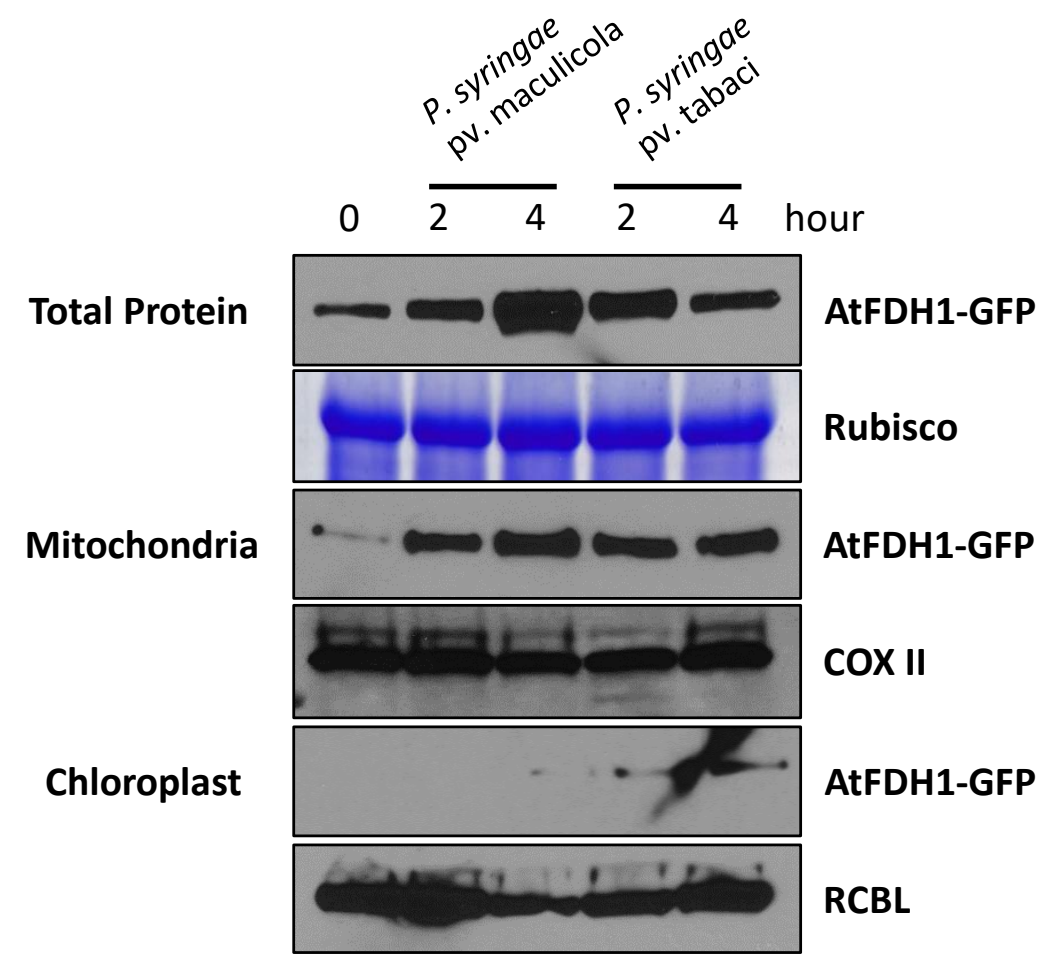

